\title{
Detection of myocardial infarction by immunohistological staining for C9 on formalin fixed, paraffin wax embedded sections
}

\author{
J P Doran, A J Howie, J N Townend, R S Bonser
}

\begin{abstract}
Aims-To evaluate an immunohistological stain for complement component $\mathrm{C} 9$ as a method of detecting early myocardial infarction and to compare this with (1) an enzyme histochemical method and (2) conventional histological staining. Methods-(1) Eight hearts taken at necropsy were stained using the nitroblue tetrazolium/phenazine methosulphate method and an immunohistological stain for C9. (2) Twenty five hearts from cases of suspected or confirmed myocardial infarction and 25 from cases without conventional evidence of infarction were stained for C9 and by haematoxylin and eosin.
\end{abstract}

Results-(1) The histochemical method indicated myocardial necrosis in five hearts and the C9 method in seven, all of which had clinical eviderce of myocardial damage or a reason for it. The histochemical method required fresh myocardium, was difficult to use and was difficult to interpret. (2) Of 25 hearts with suspected or confirmed infarction, 24 were stained by the C9 method. Staining with haematoxylin and eosin showed infarction in 16 of these, all with infarcts at least 24 hours old; the other eight had clinical evidence of infarction less than 24 hours old. The heart not stained by C9 was from a patient who, on review, had no evidence of infarction. Of the 25 control hearts, none had infarction on staining with haematoxylin and eosin, but three were stained by the C9 method. These three were from patients with septicaemia or another reason for myocardial damage.

Conclusions-The immunohistological method for C9 is a simple, reliable and sensitive method for the detection of early myocardial necrosis that could be used on formalin fixed, paraffin wax embedded necropsy material. This had advantages over a histochemical method and conventional staining with haematoxylin and eosin.

(f Clin Pathol 1996;49:34-37)

Keywords: C9, myocardial infarction.

Recent myocardial infarction can be impossible to detect either by direct examination at necropsy or using conventional stains on histological sections. Histochemical techniques can show early infarction, but these are difficult to interpret and rarely used. A method of detection of infarction that could be used on formalin fixed, paraffin wax embedded sections would be of great value.

Complement component C9, part of the C5b-9 membrane attack complex of complement, is a reliable marker of complement deposition and can be detected immunohistologically on formalin fixed, paraffin wax embedded sections of renal biopsy specimens. ${ }^{1}$ This membrane attack complex has also been found in necrotic skeletal muscle fibres ${ }^{2}$ and in infarcted myocardium. ${ }^{3}$ We wished to see whether the immunohistological stain for C9 could be used as a routine method for demonstrating recent myocardial infarction, by comparing it with an established histochemical technique, the nitroblue tetrazolium/phenazine methosulphate reaction, ${ }^{4}$ and against conventional staining with haematoxylin and eosin.

\section{Methods}

HISTOCHEMICAL STUDY

Transverse slices, about $1-2 \mathrm{~cm}$ thick, were taken from the left ventricle of eight patients at necropsy (table 1).

Nitroblue tetrazolium/phenazine methosulphate method $^{4}$

The slices of myocardium were rinsed and stored at $4^{\circ} \mathrm{C}$ in Sorensen's phosphate buffer $(0.1 \mathrm{M}, \mathrm{pH} 7.4)$ containing $0.1 \mathrm{M}$ ascorbic acid. Fresh slices were cut just before staining. These were incubated in Sorensen's buffer containing nitroblue tetrazolium, $50 \mathrm{mg} / 100 \mathrm{ml}$, and phenazine methosulphate, $2.5 \mathrm{mg} / 100 \mathrm{ml}$, for 15 minutes at $37^{\circ} \mathrm{C}$. The slices were rinsed, immersed in $10 \%$ formol saline, and photographed.

\section{Immunohistological method for $C 9$}

After fixation for at least $\mathbf{1 8}$ hours, histological blocks were cut from the myocardial slices, using the photographs as guides to the sites of blocks. Blocks were embedded in paraffin wax on a Shandon Hypercenter with a routine processing schedule. Sections were cut at $5 \mu \mathrm{m}$, dried on glass slides at $60^{\circ} \mathrm{C}$ for 30 minutes, rehydrated, and immersed in $1 \%$ hydrogen peroxide in methanol to block endogenous peroxidase. Sheep antiserum to C9 (The Binding Site, Birmingham, UK) was used at a dilution of 1 in 500 in $0 \cdot 15 \mathrm{M}$ phosphate buffered saline

Birmingham,

Department of

Medicine

Pepartmen

Department of
} 
Table1 Comparison of staining of myocardium with haematoxylin and eosin with the histochemical technique and immunohistology for C9

\begin{tabular}{|c|c|c|c|c|}
\hline $\begin{array}{l}\text { Patient } \\
\text { (sex/age in years) }\end{array}$ & Clinical details & $\begin{array}{l}\text { Haematoxylin } \\
\text { and eosin }\end{array}$ & $\begin{array}{l}\text { Nitroblue tetrazolium/ } \\
\text { phenazine methosulphate } \\
\text { staining }\end{array}$ & C9 immunohistological staining \\
\hline$F / 33$ & $\begin{array}{l}\text { Died } 24 \text { hours after heart } \\
\text { transplant }\end{array}$ & $\begin{array}{l}\text { One group of contraction } \\
\text { band necrosis }\end{array}$ & Patchy pink/red & $\begin{array}{l}\text { Extensive patchy staining of } \\
\text { single cells and groups of cells }\end{array}$ \\
\hline M/44 & $\begin{array}{l}\text { Died two months after heart } \\
\text { transplant }\end{array}$ & $\begin{array}{l}\text { Severe acute rejection with } \\
\text { patchy necrosis }\end{array}$ & Patchy pink/red & $\begin{array}{l}\text { Extensive patchy staining of } \\
\text { single cells and groups of cells }\end{array}$ \\
\hline $\mathrm{F} / 50$ & $\begin{array}{l}\text { Died one hour after collapse } \\
\text { from dysrhythmia: } \\
\text { no clinical evidence of } \\
\text { myocardial infarct: } \\
\text { coronary arteries patent }\end{array}$ & No infarction identified & Dark blue & None \\
\hline $\mathrm{F} / 55$ & $\begin{array}{l}\text { Died from septicaemic shock in } \\
\text { liver failure }\end{array}$ & No infarction identified & Dark blue & A few scattered cells \\
\hline M/62 & $\begin{array}{l}\text { Died seven days after } \\
\text { myocardial infarct }\end{array}$ & Infarcted area & White area & Heavily stained area \\
\hline M/68 & $\begin{array}{l}\text { Died two days after myocardial } \\
\text { infarct }\end{array}$ & Infarcted area & White area & Heavily stained area \\
\hline$M / 73$ & $\begin{array}{l}\text { Died } 24 \text { hours after myocardial } \\
\text { infarct }\end{array}$ & No infarction identified & Patchy pink/red & A few groups of cells \\
\hline$M / 83$ & $\begin{array}{l}\text { Died six hours after myocardial } \\
\text { infarct }\end{array}$ & No infarction identified & Dark blue & Scattered single cells \\
\hline
\end{tabular}

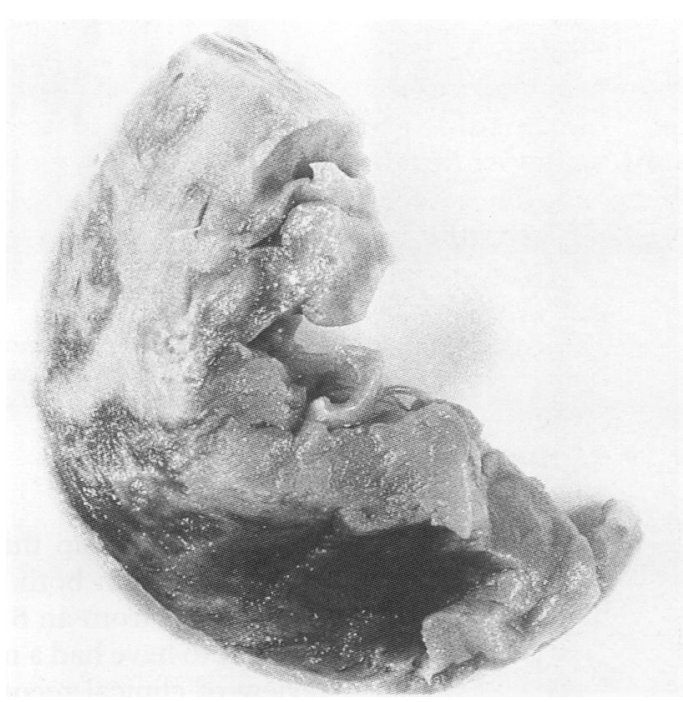

Figure 1 Slice of left ventricle from a 62 year old man stained by the nitroblue tetrazolium/phenazine methosulphate method seven days after a myocardial infarct. Non-infarcted myocardium appears dark and infarcted myocardium appears white. The junction between the dark and white areas is irregular, producing a mottled pattern at the edges of the main white area.

and applied to sections for 60 minutes at room temperature on a Shandon Sequenza immunostaining centre. After washing, peroxidase conjugated donkey antiserum to sheep IgG at a dilution of 1 in 100 was applied for 45 minutes. After another wash, peroxidase was detected with hydrogen peroxide and tetraamino-biphenyl hydrochloride (diaminobenzidine), and sections were counterstained with haemalum, dehydrated and mounted.

STUDY OF CONVENTIONAL STAINING

Necropsy records were reviewed and 25 consecutive cases with clinically suspected or confirmed myocardial infarction were identified. Another 25 cases without clinical or conventional pathological evidence of myocardial infarction were also identified. Sections of formalin fixed, paraffin wax embedded myocardium, stained with haematoxylin and eosin, were inspected. The immunohistological method for C9 was applied to sections cut from the same blocks.

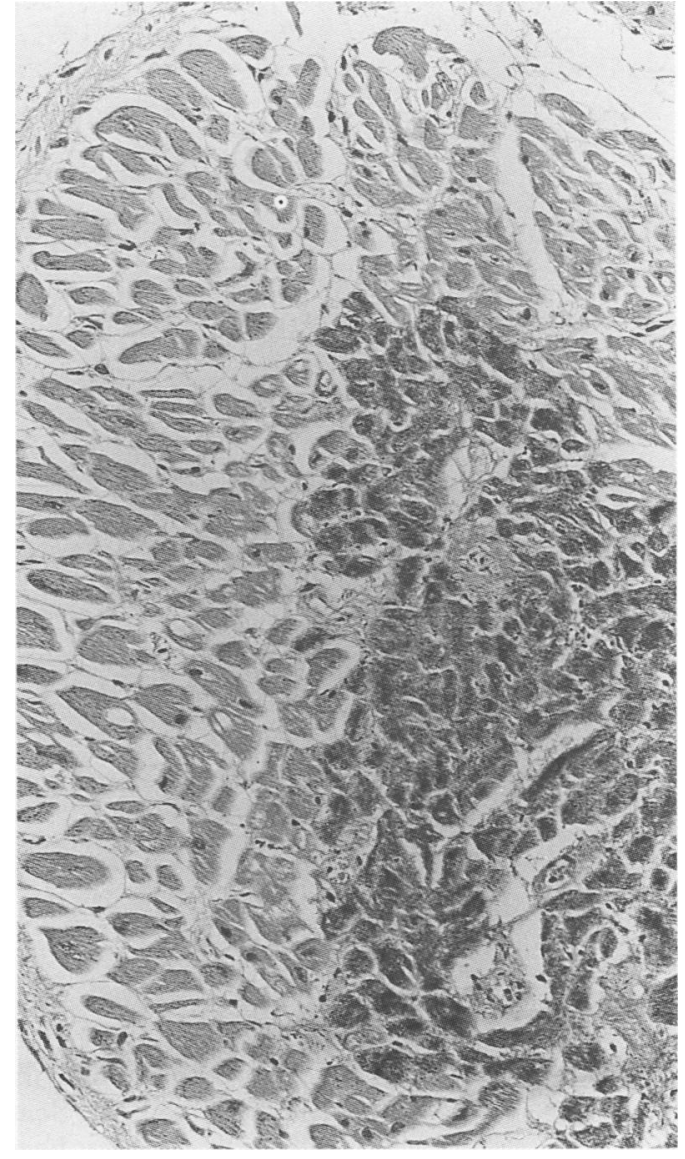

Figure 2 Histological section taken from the heart in fig 1 at the junction of macroscopically dark and white areas, stained by the immunohistological method for C9.

Infarcted myocardial cells appear dark.

\section{Results}

HISTOCHEMICAL STUDY

Myocardium without obvious infarction stained dark blue with the nitroblue tetrazolium/phenazine methosulphate method (table 1). Unstained areas, virtually white, were seen in two hearts with well established infarction (fig 1). Intermediate staining with patches of pink to red coloration was seen in three hearts.

Intracellular deposition of C9 was detected immunohistologically in the areas of infarction as defined by the enzymatic method, with 
Table 2 Comparison of staining of myocardium with haematoxylin and eosin ( $H$ and E) with immunohistology for $C 9$ in 50 hearts

\begin{tabular}{lll}
\hline & $\begin{array}{l}\text { 25 hearts with suspected/ } \\
\text { confirmed myocardial infarction }\end{array}$ & $\begin{array}{l}\text { 25 hearts without } \\
\text { obvious myocardial } \\
\text { infarction }\end{array}$ \\
\hline $\begin{array}{l}\text { H and E showed infarct; } \\
\text { C9 positive }\end{array}$ & 16 & 0 \\
H and E showed infarct; & 0 & 0 \\
C9 negative & 8 & 3 \\
H and E did not show & 1 & 22 \\
$\begin{array}{l}\text { H and E dion; C9 positive } \\
\text { infarction; C9 negative }\end{array}$ & &
\end{tabular}

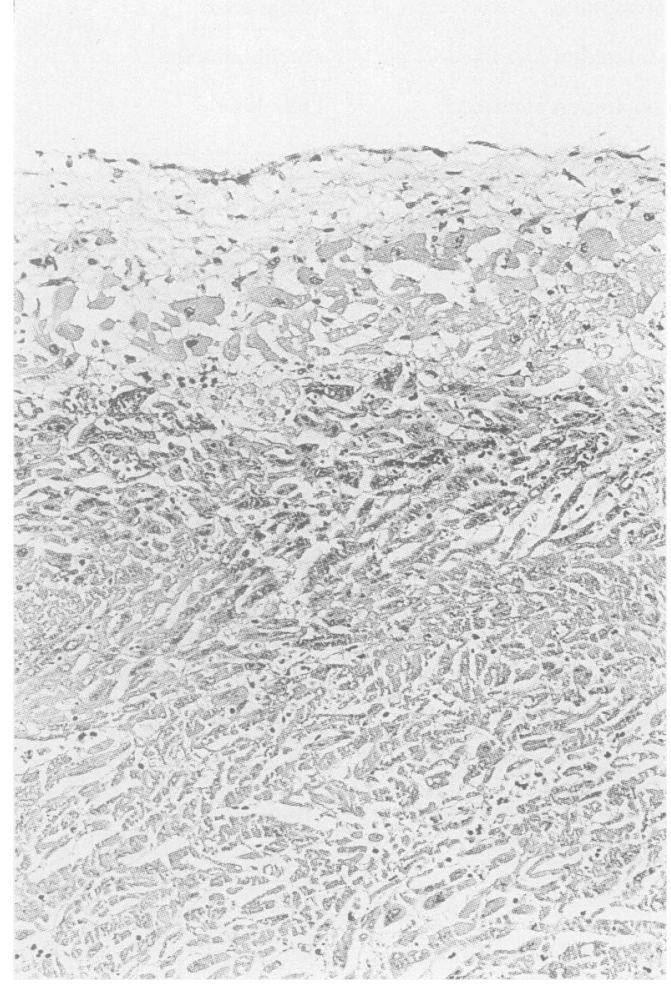

Figure 3 Immunohistological staining for C9 on a section of myocardium from a 64 year old man five days after a myocardial infarct. Subendocardial myocardium is viable and unstained, with immunostaining at the edge of a well established infarct.

greater intensity of staining at the edges of infarcts (fig 2). There was patchy staining with C9 in the hearts that had pink/red histochemical staining. Scattered single cells stained with C9 in two hearts that had dark blue histochemical staining. C9 was not deposited in muscle cells in one heart which had no clinical, conventional pathological or histochemical evidence of infarction. C9 was detected in arterial walls in viable myocardium and was a useful internal positive control in all hearts.

STUDY OF CONVENTIONAL STAINING

Comparison of conventional staining with immunohistology for C9 is presented in table 2 . The eight hearts in the group of suspected or confirmed myocardial infarction stained by $\mathrm{C} 9$ but with no conventional evidence of infarction were all from patients with clinical evidence of infarction less than 24 hours old, whereas the 16 identified by staining with haematoxylin and eosin and also stained with C9 had infarcts from 24 hours to 20 days old (fig 3 ). The single

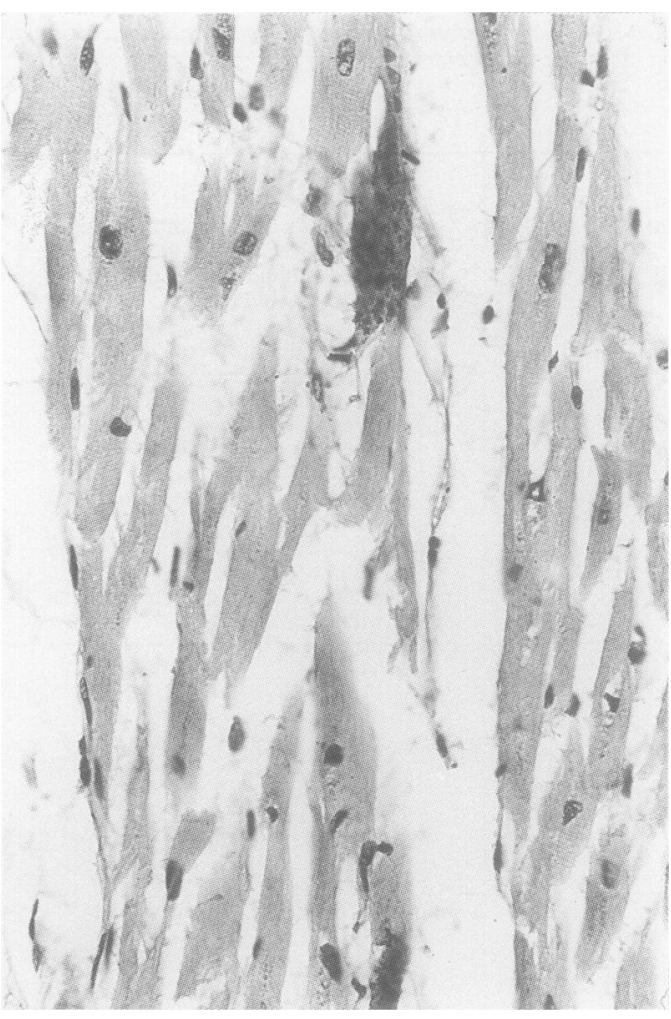

Figure 4 Immunohistological staining for C9 on a section of myocardium from a 57 year old man who died of peritonitis. Two myocardial cells contain $C 9$ and appear dark.

heart in this group that seemed to be normal on staining with both haematoxylin and eosin and $C 9$ was from an 81 year old man who was thought to have had a myocardial infarct but on review of clinical records had unstable angina without electrocardiographic evidence of infarction. Three hearts in the control group were C9 positive. These were from a 43 year old man with septicaemic shock caused by an intraabdominal abscess, a 57 year old man with peritonitis caused by a perforated gastric ulcer, and a 78 year old woman with HenochSchoenlein purpura. In these three cases a few single myocardial cells scattered throughout the sections stained positively with C9 (fig 4).

\section{Discussion}

Immunohistological staining for $\mathrm{C} 9$ was better than the nitroblue tetrazolium/phenazine methosulphate method for detecting myocardial infarction. The C9 method had the advantage that formalin fixed, paraffin wax embedded material could be used. Unlike the technical difficulties of the histochemical method, there was no need for special storage or treatment of samples from hearts. The histochemical method was unreliable on an infarct under 24 hours old, whereas the C9 method stained this infarct. The histochemical method is a macroscopic test whereas the C9 method is microscopic and permitted much finer resolution, detecting staining of single cells. The C9 method was so sensitive that it detected scattered single myocardial cell necrosis in three of the 25 hearts without other evidence of myocardial damage, but with an adequate clin- 
ical explanation for such damage. This finding was similar to that in the 55 year old woman with septicaemic shock in the histochemical study (table 1). The C9 method was superior to conventional staining for detecting infarcts less than 24 hours old. Hearts without evidence of infarction were not stained by the $\mathrm{C} 9$ method.

Activation of the complement system and deposited C5b-9 complex is known to accumulate in infarcted myocardium, both in humans $^{35}$ and experimental animals. ${ }^{67}$ Complement deposition in infarcted areas occurs after a few hours, two to four in the $\operatorname{rat}^{7}$ and five to six in the rabbit, ${ }^{6}$ except when reperfusion occurs, when complement deposition is rapid. ${ }^{6}$ This observation shows that circulating blood is necessary for the activation and deposition of complement, ${ }^{8}$ and accords with our finding that $\mathrm{C} 9$ deposition was most noticeable at the edges of well established infarcts.

The immunohistological stain for C9 has many potential uses such as in retrospective studies of hearts to detect unsuspected myo- cardial infarction and in the study of diffuse non-regional necrosis of individual myocardial cells.

We are grateful to the British Heart Foundation for a grant to support this work, and to Mrs M C Williams for technical help.

1 Howie AJ, Gregory J, Thompson RA, Adkins MA, Niblett AJ. Technical improvements in the immunoperoxidase study of renal biopsy specimens. f Clin Pathol 1990;43:257-9.

2 Engel AG, Biesecker G. Complement activation in muscle fiber necrosis: demonstration of the membrane attack complex of complement in necrotic fibers. Ann Neurol 1982 12:289-96.

3 Schafer H, Mathey D, Hugo F, Bhakdi S. Deposition of the terminal C5b-9 complement complex in infarcted areas of human myocardium. F Immunol 1986;137:1945-9.

4 Flint EJ. Phenazine methosulphate and the nitroblue tetrazolium macroreaction for recent myocardial infarction. $\mathcal{f}$ Clin Pathol 1984;37:477-8.

5 Hugo F, Hamdoch T, Mathey D, Schafer H, Bhakdi S. Quantitative measurement of SC $5 \mathrm{~b}-9$ and $\mathrm{C} 5 \mathrm{~b}-9(\mathrm{~m})$ in infarcted areas of human myocardium. Clin Exp Immuno 1990;81:132-6.

6 Mathey D, Schofer J, Schafer HJ, Hamdoch T, Joachim HC, Ritgen A, et al. Early accumulation of the terminal complement-complex in the ischaemic myocardium after reperfusion. Eur Heart f 1994;15:418-23.

7 Vakeva A, Morgan BP, Tikkanen F, Helin K, Laurila P, Meri S. Time course of complement activation and inhibito expression after ischaemic injury of rat myocardium. Am f Pathol 1994;144:1357-68.

8 Kilgore KS, Friedrichs GS, Homeister JW, Lucchesi BR. The complement system in myocardial ischaemia/reperfusion injury. Cardiovasc Res 1994;28:437-44. 